\title{
LAS CONSULTAS MÉDICAS EN LA ESPAÑA DEL SIGLO XVIII: RAZONES DE SU EXISTENCIA
}

\author{
Pilar León Sanz \\ Departamento de Humanidades Biomédicas. Facultad de Medicina \\ Universidad de Navarra
}

\section{RESUMEN}

Estudiamos cómo justifican los médicos españoles del siglo XVIII las consultas o juntas de facultativos, así como los casos en los que se recomendaba este procedimiento. En un segundo momento analizamos los requisitos del consultor y su responsabilidad profesional, y los aspectos económicos. Concluimos con una revisión de los perjuicios y críticas que ocasionaba la realización de las consultas.

PALABRAS CLAVE: historia de la medicina, España, siglo XVIII, historia de la ética médica.

\section{SUMMARY}

In this article we describe the reasons eighteenth century Spanish physicians offered to justify the consultations they held, as well as the circumstances where such procedures were recommended. The professional qualifications of the consulting physician, his responsibilities towards the attending doctor, etiquette, and the pecuniary aspects of consultations are also discussed. Finally we review the frequent criticisms and judgments against consultations raised by other doctors

KEY WORDS: history of medicin, Spain, $18^{\text {th }}$ century, history of medical ethics.

\section{INTRODUCCIÓN}

El término consulta en el ámbito profesional del médico del siglo XVIII se refiere a tres tipos de actos médicos: a los dictámenes profesionales que emanan de la asistencia al paciente, al consejo profesional comunicado a un colega o publicado por un médico y al acto por el que varios médicos se reúnen para examinar a un enfermo y discutir acerca del diagnóstico y tratamiento de la enfermedad que padece. Este último tipo también es llamado en los textos de la época «Junta de médicos» y es al que fundamentalmente aquí vamos a referirnos ${ }^{1}$.

1 LEÓN SANZ, P. (2002), «La consulta médica. Una práctica de la medicina del siglo XVIII», Dynamis 22, 279-301. 
En este artículo nos proponemos estudiar la justificación de esta práctica, es decir, la retórica que, en los textos médicos, sirve para explicar en el XVIII la necesidad de las consultas o juntas de médicos, así como los casos en los que se recomendaba este procedimiento. En un segundo momento abordaremos algunos condicionamientos derivados de este tipo de ejercicio médico: los requisitos del consultor y su responsabilidad profesional en una práctica que requiere la intervención de más de un facultativo; y, también, la cuestión económica, puesto que las juntas eran una práctica cara. Y finalizaremos con un análisis de los perjuicios y de las críticas que la realización de las consultas y juntas de médicos ocasionaban.

\section{LA RAZÓN DE SER DE LAS CONSULTAS}

\subsection{La tradición}

El primer argumento con que se justifica la existencia de las consultas médicas es el derivado de su presencia, como forma de ejercicio profesional, desde la medicina hipocrática. En nuestras fuentes es común la insistencia en señalar que «fue el Príncipe de la Medicina (Hipócrates) el primero que con vigilantísimo cuydado la adornó de sanísimos preceptos y reglas muy saludables; constituyéndola de esta suerte en un método tan racional, que ninguno de quantos Autores ha dado la posterioridad ha tenido que hazer, ni enmendar» ${ }^{2}$.

Ciertamente, en el Corpus Hippocraticum, encontramos descripciones de la atención médica prestada a pacientes referidos por otro profesional ${ }^{3}$. Pero, además, los tratadistas del XVIII como Pellaz y Espinosa ${ }^{4}$ fundamentan la realidad de esta práctica citando expresamente el libro de los Preceptos ${ }^{5}$.

Hemos encontrado la misma referencia en Enrique Jorge Enríquez, quien trata acerca de la práctica de las consultas ${ }^{6}$ y se hace eco de la advertencia hipocrática: «No carece de decoro un médico que, al encontrarse en apuro con un enfermo en un momento dado, y quedarse a oscuras por su inexperiencia, solicite que vengan otros médicos para conocer lo referente al enfermo en una consulta en común y para que

2 Pellaz y EsPinosa, M. (1708), Espejo verdadero de Consultas, que con luz participada de los Príncipes de la Medicina se manifiesta para utilidad de muchos..., Madrid, p. 5.

3 Pueden verse en las Epidemias I-III y en Las Enfermedades, o en el libro De las enfermedades de las mujeres. LITTRÉ, E. (1839-1861), Oeuvres complètes d'Hippocrates, París, VI, pp. 208-72 y VIII, p. 10.407.

4 PellaZ y EsPinOSA (1708), pp. 5 y 34.

5 Tratados Hipocráticos. Traducción GARCía GuAL, C. (1983), Madrid, Gredos 63, pp. 299-318. También, LóPEZ FÉreZ, J. A., en Tratados hipocráticos (1983), pp. 301-308; SÁNCHEZ GrANJEL, L. (1972), Traducciones castellanas de Hipócrates. Homenaje a Antonio Tovar. Madrid, pp. 169-176.

6 EnRiQuez, E. J. (1595), Retrato del Perfecto Medico, Salamanca, Colección Textos médicos españoles IV, 1981, pp. 203-8. 
sean sus colaboradores en procurar ayuda (...). ¡Jamás discutan ni se ridiculicen los médicos cuando se reúnen!. Lo que voy a decir bajo juramento es que jamás el juicio de un médico debería rivalizar con otro, ya que puede parecer signo de inseguridad $\gg{ }^{7}$.

A partir de este autor se reitera la misma cita hipocrática: la encontramos también, por ejemplo, en un tratado sobre las Consultas médicas de Cristobal Francisco Luque $^{8}, \mathrm{y}$, como se ha expuesto supra, en los tratados del siglo XVIII. El pasaje se refiere a la práctica de la medicina por parte de los malos médicos, quienes especulan con el dinero de los pacientes, evitan atender las enfermedades difíciles y no llaman a otros médicos cuando el caso lo requiere. Preceptos $8^{\circ}$, como acabamos de observar, recomienda claramente la consulta con otro facultativo y señala la forma en que ésta se ha de llevar a cabo.

Pero Hipócrates no es la única autoridad invocada por los autores del siglo XVIII. Le atribuyen a Galeno el consejo de que el médico comparta el riesgo del ejercicio con un colega, lo cual es especialmente recomendable si el paciente fallece 9 .

Y ya en el ámbito de los autores modernos son aducidas referencias a otros médicos, como al ya mencionado Enrique Jorge Enríquez, a Francisco Valles, a Zacuto Lusitano, a Alfonso Ruiz de Fontecha o a Juan Bautista Montano para justificar la práctica habitual de la consulta médica ${ }^{10}$.

Las alusiones a autores del pasado están, en esta ocasión, plenamente vigentes, puesto que tratan del médico y del modo de ejercer la medicina, cuestión mucho más invariable que las relacionadas con las de carácter científico o técnico.

7 ENRÍQueZ (1595), pp. 314-315, cita Preceptos 7, que se corresponde con el no 8 en Luque, en Pellaz y Espejo y en las ediciones actuales.

8 LUQUE, C. F. (1694), Apolineo caduceo haze concordia entre las dos opuestas opiniones, una que aprueba las Consultas de los Medicos para la curación de las graves enfermedades, otra que las reprue$b a$, Sevilla, p. 8: «En favor de la consultas prosiguen médicos: está por todos Hipócrates, quien las aconseja como útiles, y aun necesarias en las graves enfermedades: Nec vero indecore se ille geret medicus, qui in rei praesentis angustia circa aegrum aliquem, \& imperitia tenebras offundente, alios quoque accersere infferit, quo ex communi consideratione, res circa aegrum inquirantur, accognoscantur, \& illi cooperatores fiant ad auxilii ferendi facultatem; nam in afflictionis assiduitate augescente affectione ob consilii inoppeam, plurima ad rem praesentem affugiunt. (Hipócrates in lib. praecet.)».

9 «No es dudable, que si muriere el enfermo, tendrá el Medico el consuelo, y mas que fuerte escudo, de averlo manifestado assi desde que conociò el gran riesgo en que estava el paciente: Infontem abolitionis crimine fore Medicum, que dixo Galen. 1.progn. com. 4. \& fol. Mihi 198. Litt. E. Dicens, quoties convaliturus, aut moriturus aegros praenuntiet», PELLAZ Y ESPINOSA (1708), p. 12. Pellaz apoya este argumento en un pasaje de Galeno que no hace referencia a la participación de más de un médico en la asistencia. Es posible que la cita pertenezca a Hippocratis Prognosticon et Galeni in eum librum commetarii. I. IV. Cfr. KÜHN (1965,1830), Hildesheim, Olms XVIII/2, pp. 5-22.

10 Pellaz y Espinosa (1708), p. 8-14. 
1.2. La salud de los enfermos y el provecho de los médicos

La razón principal por la que los autores españoles del siglo XVIII recomiendan las consultas médicas es el beneficio del enfermo. Y es el bien del paciente una referencia continua al considerar esta práctica. Como afirma Manuel de Val, el fin de la consulta no es el «provecho y lucimiento del médico», sino el bien del enfermo; y «todo lo demás es por de más y muy fuera de propósito» ${ }^{11}$. Y Francisco Mallén y Cuevas reitera: «quien no tiene su cabeza para Juntas, no la tendrá para curar; pues las Juntas se dirigen a la mejor curación $»^{12}$. Cristóbal Rodríguez de Saavedra, por su parte, asegura que la consulta es el «remedio más eficaz para la salud de los enfermos ${ }^{13}$. Incluso en las disputas publicadas a raíz de las Juntas de médicos, se argumenta su utilidad en función del bien del paciente; porque, en estos casos, como señala Monrava y Roca, «el enfermo (es) puesto en balanza» ${ }^{14}$ y el médico es «el supremo sentenciador» ${ }^{15}$.

La fundamentación de la consulta en el beneficio del paciente sitúa esta práctica en un panorama teórico más amplio que el de una deontología formal organizada alrededor de la etiqueta médica que, según señala la historiografía, supuso dar preferencia a la regulación de la relación intraprofesional más que a la relación médicopaciente. Los consejos o advertencias de la etiqueta insisten más en las normas de actuación que en el beneficio del paciente ${ }^{16}$.

Por otra parte, los médicos españoles del setecientos también están de acuerdo en que la práctica de las consultas produce un indudable provecho a los propios facultativos, ya que favorece la buena relación entre ellos y evita malentendidos: «La honorífica concordia de los médicos, en sus importantes Juntas, cierra la puerta a las escandalosas discordias ${ }^{17}{ }^{17}$. Además, esta es la mejor manera de resolver los conflictos ya creados. En este sentido, son conocidos los testimonios de las Juntas de médicos que se celebraron en los Reales Hospitales, para solucionar las controversias surgidas

\footnotetext{
11 Pellaz y Espinosa (1708), Carta de D. Manuel de Val.

12 Mallen y Cuevas, F. A. (1715), Manifiesto médico contra la censura que dio el Doct. Don Antonio Águila, médico de la Villa de Baena, aviéndole consultado acerca de la curación que se pretendía executar en cierta Señora..., Córdoba, p. 24.

13 Pellaz y Espinosa (1708), Carta de Cristoval Rodríguez de Saavedra.

14 MonRava y RocA, A. de (1750), Epistola consultiva apologética, o el Conde de Luna enfermo, o medica batalla entre un médico pigmeo y 20 gigantes, Lisboa, p. 279.

15 MONRAVA Y ROCA (1750), p. 292.

16 Cfr. BAKer, R. (1993), «Deciphering Percival's code», en BAKER, R.; PORTER, D.; PORTER, R. (eds.), The codification of Medical Morality, Kluwer, pp. 179-212; también, CHAPMAN, C. B. (1984), Physician, Law \& Ethics, Nueva York, p. 177.

17 ACUÑA, S. de (1744), Disertaciones sobre el orden que los médicos deben observar en las juntas para evitar discordias y conservar la autoridad y prerrogativa de que goza cada uno, Madrid, pp. 132-147.
} 
entre los facultativos ${ }^{18}$. De modo que los médicos aseguran que el ejercicio de la consulta es bueno para el profesional y que su práctica, tan buena y recomendable, «es la mas arreglada y segura norma de aciertos», siendo beneficiosa para el médico consultor, aun cuando el paciente sujeto de la consulta, no consiga la salud ${ }^{19}$.

\subsection{La experiencia de otros médicos}

Hemos observado que la necesidad que el médico siente de conocer la opinión de otros médicos y apoyarse en ella es otra de las razones de ser de las consultas o juntas de médicos, pues «si un consultor excede en lo phisiológico, puede otro trascender en el prognóstico» ${ }^{20}$. Y la experiencia es, en palabras de Pellaz, «el medio más eficaz y verdadero de conseguir aciertos, cualquiera que sea en la facultad médica» $\aleph^{21}$. Una de las razones por las que León Gómez recomienda que se practique la consulta médica es la capacidad formativa, a través de la transmisión de experiencias, que la consulta tiene para los participantes más jóvenes o menos doctos ${ }^{22}$.

Esta perspectiva se corresponde también con una mentalidad empírica, en la que la experiencia de casos anteriores es guía para actuar de una manera determinada. El mejor consultor es el que puede aportar mayor número de casos resueltos satisfactoriamente; con independencia de que también fundamente sus dictámenes con un aluvión de citas de autores pretéritos o contemporáneos: «La larga experiencia que en esta ciudad tenemos de sus aciertos, me haze recurrir con las esperanças de lograr el alivio del penoso achaque que padezco, aunque las consultas de estos señores están muy doctas y comprehensivas, para que Vmd. pueda mejor dirigirme, me ha parecido ponerle práctico, assi de mi complexión, como también el tiempo que estoy padeciendo, assi este como otros accidentes, que han sido el origen de él» $\gg^{23}$.

\footnotetext{
18 Por ejemplo, la disputa que hubo entre Herrero y López de Araujo: HERRERO Y RUBIA, A. M. (1756), Historia de la disputa sobre la enfermedad que quitó la vida a Manuel Rodríguez en el hospital general de esta corte..., Madrid, p. 8. O bien la suscitada entre Miguel Morago y Valentin Murcia, cfr. NuÑez Olarte, J. M. (1999), El Hospital General de Madrid en el siglo XVIII, Madrid, p. 87.

19 Pellaz y EspinOsa (1708), p. 11.

${ }^{20}$ LUQUE (1694), p. 308.

21 PELLAZ Y ESPINOSA (1708), p. 71.

22 «Lo tercero, porque también se frustra el fin menos principal, que es el aprovechamiento de los Médicos inferiores; y la honra, y crédito del mas sabio». LEÓN GÓMEZ, P. (1744), Dissertaciones morales y medicas... Y se ponen las obligaciones particulares de los professores de la Medicina natural..., Madrid, p. 19

23 SuÁrez de Rivera, F. (1726), Teatro de la salud o Experimentos médicos, Madrid, p. 253.
} 


\section{LA OBLIGACIÓN DE CONSULTAR}

Hay quien estima que llamar a otros colegas a consulta es una obligación permanente para el médico: «Suele suceder, que algunos médicos, sin oír a los demás en las Juntas, quieren determinar por si solos, como oráculos. Pues tengan entendido, que están obligados a oír el dictamen de los otros. Lo primero, porque semejante modo de proceder cede en desprecio y vituperio de los demás. Lo segundo, porque es frustrarse el fin principal de las consultas, que es inquirir y averiguar la enfermedad, su causa, y curación» ${ }^{24}$. Estos autores estiman que el acuerdo entre facultativos es siempre más acorde y acertado que la sola opinión de uno de ellos.

Se considera necesario recurrir a la Consulta o Junta de médicos siempre que el caso sea grave; siempre que existan dudas acerca del padecimiento en cuestión; y cuando ha fracasado el tratamiento. También, por supuesto, si la familia desconfía del médico o del tratamiento prescrito.

Otra causa de convocatoria de las consultas, ya de carácter opcional, es dirimir las discrepancias planteadas entre colegas.

\subsection{En los casos graves}

Todos los teóricos de la consulta son unánimes al determinar que siempre es preciso realizar una consulta ante los casos graves ${ }^{25}$, incluso cuando no haya dudas respecto al diagnóstico y al tratamiento que se haya de seguir. La influencia de la opinión de un médico puede ser decisiva para la vida del enfermo, por lo que el profesional no se debe fiar únicamente de su criterio. «Por más docto, y experimentado que sea el médico», tiene que contar con otros para evitar descuidos que pueden ser fatales para el enfermo ${ }^{26}$. Por eso Pellaz y Espinosa recomienda «que en lo grave de las enfermedades se soliciten, y busque otros ojos ${ }^{27}$. Además, así estaba previsto en las Constituciones de algunos Centros, como en las del Hospital General de Madrid: «En los casos arduos que se ofreziesen así en las enfermerías de los hombres como en las de las mugeres se juntaran los médicos para verlos, y proveer lo que conbiene a la salud del enfermo» ${ }^{28}$. También León Gómez apoya que en esos casos

\footnotetext{
24 LEÓN GÓMEZ (1744), p. 19.

${ }^{25}$ Es una recomendación presente ya en Enríquez: «hara muy decentemente el médico, si viendo a su enfermo en peligro, mandare llamar otros, para que con la común consideración y consulta de todos se inquieran los remedios, y se hagan mas diligentes para le poder remediar». ENRIQUEZ (1595), pp. 203-204.

${ }^{26}$ Pellaz y ESPINOSA (1708), p. 10.

27 Ibidem.

28 NUÑEZ OLARTE (1999), p. 65.
} 
se realice una junta ${ }^{29}$ y añade esta recomendación: el médico ha de aceptar de buen grado que la familia pida que se haga una consulta cuando la gravedad del enfermo es manifiesta ${ }^{30}$.

\subsection{En los casos dudosos}

Si el origen de la consulta se apoya en una razón de prudencia por parte del médico, nada más lógico que plantearlas cuando surgen dudas: «En lo más intrincado y dudoso de las morbosas hostilidades, es la consulta precioso eslabón que con las brillantes luzes, que en fuerça de la emulación misma despiden los entendimientos de los que concurren a ella, se acrisola, y purifica lo más conveniente, lo más arduo y arriesgado del morbo» ${ }^{31}$.

De igual forma que sucede con los enfermos graves, parece obligada esta práctica en los casos dudosos, ya que «podemos venir en conocimiento de las dolencias que afligen a nuestra naturaleza, por medio de el deleytable y gustoso trato de las consultas» $»^{32}$. Pellaz abunda en la cuestión: «Solicite, pues, el médico (...) se le trayga acompañado, por quanto, aunque más prudente y avisado sea, es cierto que, en la ocurrencia de otros, serán más ardientes sus conatos» ${ }^{33}$.

La llamada a la consulta, cuando el caso es dudoso, llega a ser un deber - que León Gómez considera ineludible - porque lo contrario sería «exponer al enfermo a daño grave $»^{34}$.

\subsection{Ante el fracaso del tratamiento}

Este supuesto es la causa que movió a convocar un buen número de las consultas que han sido publicadas ${ }^{35}$. En estos casos, suelen ser planteadas, o bien por los facul-

\footnotetext{
29 «Puede el médico pedir acompañado en los casos arduos, y dificultosos, aunque no se le ofrezca duda en lo que ha de hacer: porque de esta suerte se atiende mejor al bien del enfermo», LEÓN GÓMEZ (1744), p. 18.

30 «el médico no se ha de sorprender y mucho mejor podrá aceptarle en semejantes casos, quando en la casa se lo propongan», LEÓN GÓMEZ (1744), p. 18.

31 PellaZ Y EsPinOSA (1708), p. 5.

32 Ibidem, Carta de D. Manuel de Val.

33 Ibidem, p. 7.

${ }^{34}$ LEÓN GÓMEZ (1744), p. 18.

35 Por ejemplo las de: SuÁREZ DE RIVERA, F. (1721), Resoluciones de consultas, Madrid; OXEA, F. (1777), Disertación Medica de la sinplicidad, i sencillez con que se debe ejercer la medicina, Santiago; MONRAVÁ Y ROCA (1750); ADEVA Y PACHECO, J. (1754), Verdadera medicina y desengaño de la adulación médica, Madrid.
} 
tativos que no han conseguido alcanzar los objetivos terapéuticos pretendidos, o bien por los pacientes y sus familiares, ante la persistencia de los males. Ejemplo de lo primero es la «Consulta que el doctor don Manuel Bravo de San Pedro, médico titular de la Villa de Jarandilla, hizo al Autor sobre unos dolores artríticos, productos de fermento venéreo ${ }^{36}$. En cambio, en una consulta planteada al Dr. Monravá y Roca, la iniciativa es del paciente: la recomendación de un amigo «me determinó a buscar de dicho médico Monrava, un consejo sobre mis enfermedades ${ }^{37}$.

Bastantes de los pacientes objeto de estas consultas, habían sido tratados con múltiples remedios, tanto por la ineficacia de los medicamentos, como por la polifarmacia tan en uso en la época: «Son tantos los remedios que han executado estos médicos, que si no tuviera tan buen estómago, fuera imposible el proseguir: los jarabes han sido muchos, las purgas repetidas, píldoras de goma, y azero, sales volátiles oleosas, diversas unturas, pero todo no me ha aliviado en nada $\rangle^{38}$, razón por la cual el paciente formula la consulta a Suárez de Ribera ${ }^{39}$. Y Oxea nos traslada la consulta que recibió por carta: «Consulté dos profesores i ambos resolvieron aplicarme sanguijuelas, diferenciándose su parecer en que el uno caminó conmigo en no tomar medicina; sí una especie de té con varias yerbas i azúcar de pilón i en cada toma 5 gotas de elixir conpuesto por el famoso Hoffman, (...), el otro me recetaba una purga antes de las sanguijuelas, unturas con grasa de oso a las partes lesas i otras cosas» ${ }^{40}$.

\subsection{Por la desconfianza en el médico}

En otros casos, los pacientes padecen enfermedades raras: «Muy señor mío — se lee en la carta al Dr. Suárez de Ribera-, me mueve a consultarle una enfermedad, que no he encontrado en Autores que he leído, porque es particular y rara; y aunque lo he consultado en Madrid con médicos, y en Murcia con cirujano afamado, de parte alguna he podido conseguir la salud de una enferma, que es hija mía, aunque he

\footnotetext{
${ }^{36}$ Este médico presenta una paciente de 34 años a la que no consigue aliviar pese a la multitud de remedios usados. Termina: «Y con esto he puesto fin a este dictamen, el qual protesto sujetar a otro, cuyas razones me hagan fuerza, pues siempre he deseado oír con gusto las de los que con justificada razón deben ser tenidos por maestros de la Medicina, aunque se dirijan a amonestar, y enmendar mis errores»; SUÁREZ DE RIVERA (1721), p. 253.

37 MONRAVA Y ROCA (1750), p. 277.

38 SUÁREZ DE RIVERA (1721), p. 255

39 «Vmd. verá essas Consultas con al reflexion que acostumbra, y yo espero, por lo notorio que me son sus aciertos, me ordene lo que debo executar, como assimismo muchos preceptos de su agrado»; SUÁREZ DE RIVERA (1721), p. 255. Del mismo tipo es el caso que comienza: «Informe que don Juan Antonio de Celaya y Vicente haze al Autor, sobre el penoso achaque que padece»; SUÁREZ DE RIVERA (1721), p. 253.

40 OXEA (1777), p. 60.
} 
hecho lo que me han recetado» ${ }^{41}$. Y Piñera y Siles plantea una consulta pública «por sus particulares, por la moción que ha causado en las gentes, por la emulación que ha suscitado, por las contradicciones que me ha hecho padecer, por las críticas que ha motivado» la atención clínica a un atarantado ${ }^{42}$.

Este tipo de consultas prestigian al consultado y, en ocasiones, ponen de manifiesto la desconfianza del paciente o de la familia en los facultativos que le han atendido antes. Adeva nos ha transmitido diversos ejemplos. En uno de ellos declara haber puesto al descubierto a un impostor ${ }^{43}$. En otra ocasión fue requerido por el consejo de una población cercana a su domicilio que desconfiaba de los conocimientos del médico local ${ }^{44}$.

\subsection{Para resolver discrepancias}

Por último, otra causa de la convocatoria de las consultas, aunque ya no tiene un rango de obligatoriedad - es dirimir las discrepancias planteadas entre colegas. Un ejemplo son las llamadas consultas de «desempate», que se realizaban en presencia de nuevos médicos consultores, cuando no se había llegado a un acuerdo entre los anteriores. Es el caso de la «Tercera Consulta» practicada en Madrid acerca de la enfermedad del Conde de Luna: «Uno de ellos leyó primero la consulta de los ocho médicos con alta, espaciosa y clara voz (...) Luego después otro médico leyó la otra consulta, que es la de Monravá (...). Y resolvieron todos unánimes (...). Así fue concluida la Junta» ${ }^{45}$.

Como bien destacaba Mallén y Cuevas en el relato sobre las turbulentas relaciones que tuvo con el médico Antonio Aguila, a propósito de una paciente: más vale resolver las discrepancias de forma directa y clara en una consulta que andar murmurando acerca de otro facultativo: «Quiero bolver por el compañero, aunque anda

\footnotetext{
41 SuÁREZ DE RIVERA (1721), p. 348.

42 PIÑERA Y SILES, B. (1787), Descripción histórica de una nueva especie de Corea o baile de San Vito originaria de la picadura de un insecto que por los fenómenos seguuidos a ella se ha creído ser la tarántula ..., Madrid, p. 7.

43 Tras una consulta, Adeva denuncia la prescripción inadecuada de un remedio por parte de un médico desconocido en el lugar, tras lo cual: «Tomó la palabra el boticario y dijo que se aplicase si havia de seguir tan noble Facultad, porque si según como la presente le sucederían muchos estragos; y aun le amenazó se daría cuenta al Tribunal del Real Portomedicato, informando de sus desatinos». ADEVA Y PACHECO (1754), pp. 28-38.

44 «Hubo una epidemia en Sotillo de Ladrada en 1744, como no se curaban los del pueblo, le pidieron al Médico que consultara. Se disgustó el Médico y se negó a hacerlo, «Entonces el Consejo del pueblo se reunió y determinaron llamar a consulta al Dr. Adeva, aunque no quisiera el Médico Titular... Al cabo de los días se enteró de que la epidemia había cesado y que el Concejo estaba buscando otro Médico», ADEVA Y PACHECO (1754), pp. 40-51.

45 MONRAVA Y ROCA (1750), p. 295-8. 
haciendo platillos conmigo en las casas entre sus comadres, que más valieran que estos platillos fueran Juntas» ${ }^{46}$.

\section{EL CONSULTOR}

\subsection{La idoneidad del consultor}

En la literatura médica del siglo XVIII son abundantes las referencias a las cualidades que determinan la idoneidad del médico consultor, lo cual no es algo novedoso. Se muestra en continuidad con textos de siglos anteriores en los que con frecuencia se teoriza acerca de la definición y los valores del médico, sobre todo en lo que respecta a las virtudes con los colegas ${ }^{47}$. La publicación de Pellaz y Espejo tiene esa finalidad: enseñar a practicar las consultas, ya que, según afirma, los médicos jóvenes cuando «se les ofrece alguna consulta apenas saben dar el mínimo paso con acierto para su execución» ${ }^{48}$.

Y Francisco Luque, de quien Hernández Morejón dijo que había escrito el mejor libro sobre las consultas médicas ${ }^{49}$, manifiesta que el médico consultor, además de saber mucha medicina, ha de poseer virtudes, pues no son suficientes, en este caso, aquellos conocimientos científicos que podrían bastar cuando se atiende individualmente a un paciente ${ }^{50}$. Y los buenos hábitos a los que se refiere tienen que ver directamente con el talante ético del consultor, condición que juzga imprescindible para poder asistir con acierto a un enfermo a través de este procedimiento: «Deseo persuadir que el consultor lleve el ánimo más instruido de morales documentos, que adornado el entendimiento de rudimentos naturales $\rangle^{51}$.

Los historiadores han detectado como propios, a resultas de la influencia de la secularización producida en el Siglo de las Luces, los cambios en la estimación de los valores que los médicos reconocen: lo relacionado con las llamadas virtudes cardina-

\footnotetext{
46 MaLlen y Cuevas (1715), p. 24.

47 Un estudio sobre esta cuestión puede verse en ENGELHARDT, D. von (1985), «Virtue and Medicine During the Enlightenment in Germany», en SHELP, E. (ed.), Virtud and medicine. Explorations in the Character of Medicine, Dordrecht, p. 63 y ss.

48 PellaZ Y ESPINOSA (1708), prólogo.

49 Hernandez Morejon, A. (1842-52), Historia bibliográfica de la Medicina Española, Madrid, VII, p. 197.

50 «En dos ocasiones considero exercitando al Médico, porque, o cura solo, o consulta acompañado; en el segundo empeño es el médico consultor: (...) para el primer ministerio sea docto (...); pero para el segundo empeño lleve curado el ánimo, sea Médico de si mismo, que si no está sano el ánimo, y se deja rendir al vulgar exceso de pasiones, cuando consulta, ni será consultor, ni Médico». LUQUE (1694), pp. 19 y 20.

51 «que sin los aciertos de la Ethica, no se hallan, ni aun se solicitan convenientes medios, para curar con acierto». LUQUE (1694), p. 20.
} 
les de prudencia y sabiduría, moderación y templanza, fortaleza y justicia y, desde luego, con la caridad, evolucionaron, como señala Engelhardt, hacia otras más propias de una sociedad burguesa y más formal ${ }^{52}$. No es este nuestro caso. Los documentos estudiados, incluso los fechados a finales de la centuria, no muestran tales cambios, por lo que este periodo podría considerarse más ligado al pasado que a las perspectivas ilustradas, ya que las actitudes más recomendadas para ser médico consultor guardan relación con las virtudes siempre aceptadas. Lo que sí se observa es un gran interés porque el paciente aprecie no sólo los conocimientos sino también los valores morales del consultor. Dejamos para otra ocasión el referirnos a la consideración que tiene para la sociedad la figura del médico-consultor, en un momento en que se habla y se escribe mucho acerca de la Medicina y de los médicos.

Como veremos a continuación, los médicos, al mismo tiempo que hacen consideraciones acerca de la prudencia, de la sagacidad, de la moderación, o de otras virtudes, se refieren al sentido del honor del médico ${ }^{53}$ y señalan que todas ellas están ordenadas al dominio del amor propio y al ejercicio de la caridad con los colegas, con el fin de favorecer el buen entendimiento entre los consultores, requisito que juzgan imprescindible para lograr la salud del enfermo: «Que nuestras disputas no han de ser pendencias, y que nuestras conferencias han de llevar por fin la salud, y el bien común, no el particular suyo» ${ }^{54}$. Tales recomendaciones debían de ser muy necesarias, a juzgar por el tono negativo con el que son expuestas, por la cantidad de ejemplos que expresan males derivados de no vivirlas y por la insistencia en practicar las consultas según el modo establecido.

La prudencia es la primera virtud recomendada al consultor, ya que «el consultar (...) únicamente pende de la prudencia $»^{55}$. La prudencia conduce a no creerse poseedor de todo el conocimiento valorando las aportaciones de los demás consultores ${ }^{56}$, a oír igualmente y sin irritación el propio dictamen y su contrario ${ }^{57}$. Esta virtud es, en

\footnotetext{
52 Así lo observa ENGELHARDT (1985): «Changes were evident in the world of the Baroque as middle-class virtues expanded in opposition the aristocratic virtues of industry, obedience, justice, and modesty», p. 63.

53 Hay numerosos estudios sobre la importancia del sentido del honor en los médicos del s. XVIII, por ejemplo: WADDINGTON, I. (1975), «The development of Medical Ethics. A sociological analysis», Medical History, 19, pp. 36-51. También BAKER (1993), pp. 179-212

54 PELLAZ Y ESPINOSA (1708), p. 13.

55 Ibidem.

56 «¿Cómo se dexará persuadir el que piensa que todo lo sabe? Cómo tolerará tener compañero el que vive con satisfacción de que él solo merece renombre de dispensador de saludes?», LUQUE (1694), p. 24

57 «Sea prudente el médico consultor, oiga con igualdad su dictamen, y el opuesto; que si el propio le lisongea, y le irrita el contrario, no podrá lograr aciertos el entendimiento en arduas dificultades», LUQUE (1694), p. 71
} 
opinión de Luque, el valor que más importancia tiene en la resolución de las siete consultas médicas que recopila en su obra ${ }^{58}$.

La virtud de la prudencia inclina a la petición de consejo, ya que «solo el prudente consulta y solicita estraño parecer en las cosas arduas, y difíciles; no fiándolo a su capricho, por más satisfacción que tenga de si mismo», dice Sánchez de Murga ${ }^{59}$. Pellaz añade: «Pues es indubitable que, quanto mas se oye con cuydado y advertencia, tanto mayores noticias se adquieren ${ }^{60}$ y que «quanto más rico, quanto más poderoso, quanto más sabio, quanto más prudente sea este o el otro, tanto más necesita del auxilio, consejo y amparo de los demás» ${ }^{61}$. «Luego, consultor y prudente son dos voces y un significado (...). Prudente debe ser el que consulta consigo, pero prudentissimo el que consulta con otros; el que consulta consigo cumple con una prudente elección, el que consulta con otros, necesita de la rectitud del ánimo mas vigor: porque no siempre es virtuosa la emulación» ${ }^{62}$.

Hay personajes bíblicos como Moisés o David que sirven de ejemplo ${ }^{63}$. Y es reiterado el recurso a la autoridad de los clásicos como Aristóteles ${ }^{64}$, Platón ${ }^{65}$, Cicerón o Séneca ${ }^{66}$ para apoyar la necesidad de pedir consejo a los colegas.

Observamos idéntica orientación en las recomendaciones acerca de la sagacidad: «Para ser buena consulta, debe executarse con notable sagacidad, solercia y prevención. Esta sagacidad o solercia solamente tiene por objeto aquello que reconoce ser más conveniente, en orden a conseguir el fin al que se aspira», afirma Pellaz ${ }^{67}$. A lo que agrega la recomendación de la moderación: «Veo ser necesario, que dicho médico consultor sepa refrenar los estímulos que pueda ocasionarle su pasión» y prosigue, pues «debe constar a todos lo muy importante que es que los médicos consultores desasidos de todo amor propio, se corrijan al más sabio, y acertado parecer, para que así logren toda estimación, y asimismo el doliente expuesto a menos contingencias, consiga la deseada salud» ${ }^{68}$.

\footnotetext{
58 LUQUE (1694), p. 22.

59 SÁNCHEZ DE MURGA, J. (1731), Consulta chirurgica contra el parecer de el Dr. D. Thomas Buiso, Córdoba. Aprobación del doctor Andrés Antonio García Faxardo.

60 PellaZ y EsPinOSA (1708), p. 7.

61 Ibidem, p. 11

62 LUQUE (1694), p. 21.

63 «Según consta en las Sagradas Letras, asi lo hizieron el Propheta Moysen, y David; pues el uno tomó el consejo de su cuñado Jetro, y el otro se rindió al parecer de una muger, pareciéndole mucho mejor que aquel que él avia determinado», PELLAZ Y ESPINOSA (1708), p. 8.

64 Ibidem, p. 7.

65 Ibidem, p.14-15.

66 Ibidem, pp. 13-15.

67 Ibidem, p. 13

68 Ibidem, pp. 24 y 33. Del mismo modo lo manifestaba LuQUE (1694), p. 72.
} 
El dominio del orgullo, tan subrayado por estos autores, ha de evitar preferir la propia opinión a la de los demás, ya que la diversidad enriquece y favorece al enfermo siempre que se siga el parecer más sabio ${ }^{69}$. Por eso hay que ser capaz de cambiar de postura en una discusión ${ }^{70}$; aunque según el Dr. Gazola, «son poquísimos los sabios que verdaderamente entienden y llegan con tiempo a mudar de consejo; $y$, por el contrario, innumerables los ignorantes obstinados $\gg{ }^{71}$.

El médico consultor debería ser capaz de reconocer los errores, pues «la confesión, de hierros, y la enmienda de ellos está reservada para los hombres doctos y de animo eroyco» ${ }^{72}$. Aunque no coincida con la opinión de otro facultativo, el consultor no ha de ser injurioso ${ }^{73} ; \mathrm{y}$, sobre todo, ha de evitar, como dice Acuña, despreciar a los otros consultores: «Pero en estar laureado un médico, no es medio para que desprecie a los demás pues algunos viéndose doctores, se visten de tanta arrogancia, que desprecian a los demás; y esto no es bien parecido, aunque sea erudito y experimentado» ${ }^{74}$, incluso como Monrava señala, cuando no se coincide, se puede criticar sin necesidad de ofender o satirizar ${ }^{75}$. Poseer estas actitudes es especialmente importante para quien preside la Junta, a quien, además, se le pide tener experiencia en el proceder que ha de seguirse en este modo de asistencia ${ }^{76}$.

Finalmente, interesa añadir una recomendación en la que insiste Adeva, médico rural y eminentemente práctico: la necesidad de la veracidad, de la sinceridad absoluta del médico con el paciente. Una y otra vez insiste en que el buen médico no es el que adula al paciente para que mantenga una actitud favorable hacia el galeno, sino el que veraz y seriamente advierte al enfermo de la situación en la que se encuentra; el que se propone a si mismo «abrir los ojos del desengaño», pues «la adulación médica

\footnotetext{
69 «Ha procurado persuadir a los médicos consultores, que notando la mucha diversidad que ay entre si mismo, se sujeten en beneficio del paciente al mas sabio, y acertado parecer, avrá alguno, que arrebatado de amor propio, inmediatamente me diga: pues, y mi punto, y propia estimación? Por ventura la he de dexar atropellar de alguno de mis compañeros?». PELLAZ Y ESPINOSA (1708), p. 22.

70 Paso a dezir al médico consultor, que de ninguna suerte es contra su punto, ni estimación el mudar del dictamen que de primero hubiesse hecho, o ya en orden al conocimiento de la enfermedad, o ya también sobre la elección de remedio, si después en vista de lo que discurriesen los compañeros, se reconociese que dicho dictamen no es conforme a razón». PELLAZ Y ESPINOSA (1708), p. 23.

71 Gazola, J. (1788), El mundo engañado por los falsos médicos. Discurso del Dr. Josef Gazola 1716, Valencia, pp. 16-17.

72 MONRAVA Y ROCA (1750), p. 107.

73 «El crítico no tiene por fin injuriar a persona alguna; porque su fin es solo enmendar innumerables hierros, y engaños». MONRAVA Y ROCA (1750), p. 107.

74 ACUÑA (1744), p. 138.

75 «No es lo mesmo reprobar doctrinas, que tratar de ignorante al Autor de ellas. Muy bien se puede criticar, sin satirizar, ni offender». MONRAVA Y ROCA (1750), p. 107.

76 «Quando se necesita que el médico que haya de presidir sea bastante exercitado en la práctica y experimentado, para que en las consultas resuelvan lo mejor para las curaciones de los enfermos». ACUÑA (1744), p. 143.
} 
es siempre un engañoso error $\rangle^{77}$, acreditada por la vulgaridad, ya que se origina de la presunción y de la ignorancia; y es algo que no facilita ni la curación, ni la prevención «porque el buen Medico sin adulaciones debe desengañar y aconsejar a los sanos lo que deben observar para que no enfermen $\rangle^{78}$. No cabe duda que estas afirmaciones son una valiosa aportación desde la asistencia; las cuales conectan con debates futuros acerca de qué se debe informar al paciente; tema tan presente en obras de ética médica como las de Percival, Gregory o, ya en el siglo XIX, del español Janer ${ }^{79}$.

Los documentos que analizamos no sólo señalan hábitos positivos o virtudes, también enumeran los vicios que hay que evitar en la consulta: «despréciense los temerosos, arrogantes, alborotados y sobervios, no se nombren, dexense en el olvido» ${ }^{80}$. Relación a la que habría que añadir la envidia al colega, con su correlato de murmuraciones, calumnias entre profesionales, etc. Malos hábitos para cualquier actividad, pero más en el caso de las consultas en las que los facultativos son elegidos frente a otros por su fama y prestigio ${ }^{81}$.

Se puede concluir de todo ello que las adecuadas condiciones ético-morales del consultor condicionan el éxito de la consulta ${ }^{82}$.

Por otra parte, en el tipo de virtudes recomendadas y en el análisis de la argumentación utilizada por estos autores, reconocemos una concepción de la relación médico-enfermo de corte paternalista que se hace bien explícita en las consideraciones de León Gómez. En el capítulo sobre las «Obligaciones de los médicos en las Juntas» subraya que esta práctica hace a los médicos «dignos de ser estimados, honrados y venerados con tres honores: con honor de subvención o socorro para su manutención: con honor de obediencia executando los enfermos lo que en provecho suyo recetan y con honor de reverencia como a bienhechores suyos $\rangle^{83}$. Puesto que la consulta beneficia al enfermo y se hace por su bien, éste ha de responder con docilidad a las indicaciones y con respeto a quien vela por él.

77 AdEVA Y PACHeCo (1754), pp. 11 y 12.

78 Ibidem, Censura de Diego Peralta.

79 Cfr. GRegory, J. (1803), Discurso sobre los deberes, qualidades y conocimientos del médico. Madrid; Percival, T. (1803), Medical Ethics; or a code of Institutes and Precepts, adapted to the professional conduct of physicians and surgeons. Manchester; JANER, F. (1831), Elementos de Moral Médica. Tratado de las obligaciones del médico y del cirujano, en que se exponen las reglas de su conducta moral y política en el ejercicio de su profesión. Barcelona. Sobre este último autor LEÓN, P. (1997), «El deber de confraternidad en los médicos. Un modelo del siglo pasado», Revista de Medicina de la Universidad de Navarra, XLI (2), pp. 126-131.

${ }^{80}$ ACUÑA (1744), p. 147.

81 ADEVA Y PACHECO (1754), pp. 6-7.

82 Son numerosas las recomendaciones sobre esta cuestión. Por ejemplo: «Hágase con acierto la elección de los médicos para las consultas, solicítense iguales en la prudencia y se lograrán aciertos ..., pero los imprudentes médicos, los temosos, alborotadores, soberbios y arrogantes, olvídense para las consultas». LUQUE (1694), p. 345.

83 LEÓN GÓMEZ (1744), p. 2. 
En los relatos de las consultas, los médicos subrayan la actitud de veneración, acatamiento y agradecimiento de los enfermos o familiares para con los consultores, muy propia de la tradición médica. De todas formas, esta percepción transmitida por los médicos difiere de la que nos ha llegado proveniente de las fuentes literarias, en las que se advierte una visión menos positiva hacia la actuación facultativa.

\subsection{Los hábitos intelectuales}

Las consideraciones acerca de las cualidades del médico consultor no finalizan con el repaso de las virtudes de carácter moral. El médico, para que pueda ser llamado a una consulta o junta, tiene que poseer hábitos de tipo intelectual, como el del estudio, puesto que la antigüedad en el ejercicio, por si sola no hace mejores a los médicos: «que no consiste el ser práctico en tener muchos años i en firmar muchas recetas, tal vez disparatadas, como las estoi viendo todos los días $»^{84}$. Ahora bien, esa formación ha de comprender la teoría y la práctica, ya que, como asegura Adeva: «el médico perfecto, quando más talentos ha adquirido de doctrina y prácticamente bien fundada, sabe profundizarse más y más (...). A este deben los enfermos buscar para sus dolencias $\rangle^{85}$.

Estos autores introducen en su discurso la repercusión que tienen en la práctica cuestiones debatidas en ese momento y que guardan relación con la epistemología de la medicina: el valor de la lógica en los razonamientos médicos, la posibilidad de la certeza en el conocimiento clínico o el escepticismo radical ante un juicio médico. Como explica Monravá, todo esto influye en las consultas, porque «la mayor parte de las disputas nace de que no entendemos bien las definiciones de los nombres y cada uno las toma en su sentido» ${ }^{86}$. Se reconoce la repercusión de la inestabilidad doctrinal en la práctica médica ${ }^{87}$.

Quizá por eso Martín Martínez insista en su Philosophia sceptica que se ha de aplicar la lógica en las consultas: «Solo tengo que añadir, como nos la pintan, hacen muy mal en no aprenderla, o no ussarla (...) los médicos en sus Juntas» ${ }^{88}$.

84 OXEA (1777), p. 86

85 ADEVA Y PACHECO (1754), p. 6.

86 MONRAVA Y ROCA (1750), p. 12.

87 GRACIA GUILLÉN, D. (1987), «El nacimiento de la clínica y el nuevo orden de la relación médicoenfermo» Cuadernos Hispanoamericanos 446-447, pp. 269-282; y HARLEY, D. (1993), «Ethics and dispute behavior in the career of Henry Bracken of Lancaster: Surgeon, Physician, and Manmidwife», en BAKER PORTER, R.; PORTER, D.; PORTER, R. (eds.) (1993), p. 47 y ss.

88 MARTINeZ, M. (1750), Philosophia sceptica, extracto de la Physica antigua, y Moderna, recopilada en diallogos, entre un Aristotelico, Cartesiano, Gasendista, y Sceptico, para instrucción de la curiosidad Española, Madrid, p. 327. Monravá también plantea la dificultad para determinar la veracidad o 
En este aspecto coinciden con las recomendaciones que hace F. Hoffman en su Medicus Politicus, en el que estima que resulta fácil llegar a un acuerdo entre dos consultores si ambos tienen un lenguaje común y coinciden en los puntos centrales de la doctrina médica, pues de otra manera, diferirán en el tratamiento, en el diagnóstico y en el pronóstico de un mismo caso. En esa circunstancia, los médicos se verán obligados a escribir sus relatos e intentar llegar a un acuerdo. Nada hace más daño a la reputación de los médicos — añade Hoffman- que la comparación de dos escritos con diferentes enfoques y opiniones ${ }^{89}$.

\subsection{La responsabilidad profesional del consultor}

Puesto que la práctica de la consulta requiere la intervención de más de un facultativo, resulta obligado analizar cuál era y cómo se determinaba la responsabilidad profesional de cada uno de los intervinientes, teniendo en cuenta que, al concluir la reunión, se emitía un dictamen conjunto con las recomendaciones clínicas que debían seguirse.

La advertencia de la responsabilidad de cada uno en la consulta viene de atrás y, ya en el siglo XIV, Henri de Mondeville criticaba la falta de diligencia personal cuando la asistencia es conjunta: son menos solícitos, porque individualmente consideran que no les incumbe la cura y que les toca a los otros ${ }^{90}$.

Queda claro que para los autores del siglo XVIII español que hemos revisado, existía conciencia de la responsabilidad individual del médico consultor. Buena prueba de ello son las críticas que recibe el comportamiento contrario; y había quien, como Gazola, se oponía a las Juntas porque en la práctica podía ser un modo de disminuir e incluso eliminar esa responsabilidad personal, lo cual perjudicaba en gran medida al enfermo: «porque siendo muchos los que intervienen en la curación, ninguno será culpable en particular, y así pasan por inocente mortalidad los homicidios $\rangle^{91}$. En este sentido, también se criticaba este sistema porque el informe colectivo disimulaba la ignorancia de alguno de los consultores, con lo que favorecía la mediocridad entre los médicos.

Por otra parte, encontramos referencias explícitas a la posibilidad de acogerse a la objeción de conciencia por parte del consultor: el facultativo tiene obligación de advertir lo que puede ser perjudicial para el paciente, aunque se trate de remedios

falsedad de los juicios y los tipos de razonamientos que han de aplicarse en las consultas. MONRAVA Y ROCA (1750), p. 12.

89 FRENCH, R. (1993), «Ethics in the Eighteenth Century: Hoffman in Halle», en WEAR, A.; GEYERKordesch, J.; French, R. (eds.), Doctors and Ethics: The earlier Historical Setting of Professional Ethics, USA, Rodopi, pp. 163-4.

90 Pagel, J. L. (1892), Die Chirurgie des Heinrich von Mondeville..., Berlín, p. 123.

91 GAZOLA (1788), p. 41. 
indicados en el curso de una consulta: «Estando pues firme el dictamen de aquel peligro, no puede el médico aplicar aquel remedio: porque, en fuerza de tal dictamen, influye en aquel peligro si consiente al otro, y con especialidad si hay esperanza que, permaneciendo firme en su opinión, últimamente se aplicará aquel remedio o se omitirá el del otro» ${ }^{92}$.

Las circunstancias aducidas para ceder en el propio criterio y admitir la prescripción de una terapéutica que se piensa poco adecuada son: el convencimiento mediante datos o razonamientos de lo contrario; o bien, la presunción de que el daño que se inferiría de seguir ese tratamiento fuera insignificante. Otro motivo para no objetar, quizá más significativo que los anteriores, es el de reconocer la mayor autoridad de quien tal cosa indica: «Alguna vez podrá el médico ceder su dictamen al del otro, por conocerle muy especial en el arte y a si mismo por inferior a él» ${ }^{93}$. Pero un facultativo no deberá ceder su propia opinión «por el hecho de querer congraciarse con el otro consultor, existir amistad o mera antigüedad» ${ }^{94}$.

En cualquier caso, León Gómez advierte que un médico que en conciencia difiere del dictamen de una consulta puede seguir atendiendo al paciente y seguir cobrando por ello, aunque se niegue a aplicar un tratamiento; porque lo hace en conciencia. Ahora bien, en tal caso, tendrá que justificar su actuación ${ }^{95}$.

\section{LA CUESTIÓN ECONÓMICA}

Las consultas afectan a los pacientes y a sus familias en otro aspecto: el económico. El desarrollo de las juntas era una práctica cara y abundan, a lo largo de todo el siglo, las recomendaciones y las críticas sobre este tipo de actuación médica que se apoyan en argumentos pecuniarios.

De 1716 es el testimonio de Gazola quien denuncia duramente cómo, a través de las consultas, se desangra a las familias de los enfermos. Además, descubre la práctica de las consultas mutuas: los médicos convocaban a juntas a aquellos facultativos que previamente les habían llamado para consultar. Esta conducta multiplicaba los beneficios de los médicos y podía perjudicar doblemente a los pacientes y a sus familias puesto que al incremento del gasto se añadía la falta de contraste en los pareceres, ya que acudían los que de antemano ya se conocían ${ }^{96}$.

\footnotetext{
92 LEÓN GÓMEZ (1744), p. 17.

93 Ibidem, p. 20

94 Ibidem.

95 Ibidem, p. 17.

96 «De las consultas también consiguen muchas ventajas, no solo acreditandose con recíproca aprobación sus errores, sino multiplicando el beneficio de la mutua correspondencia en ocasiones semejantes». GAZOLA (1788), p. 41.
} 
Hacia la mitad de la centuria, León Gómez también critica que hubiera médicos que condicionaran la continuidad de la asistencia a un paciente a la realización de consultas que no eran pedidas ni deseadas por el enfermo, por el gasto que ello producía para enfermos y familiares. Tal modo de proceder suponía, a su modo de ver, una clara injusticia; y, de igual modo que Gazola, denuncia el «monopolio médico» de semejante práctica ${ }^{97}$. El médico puede, por supuesto, solicitar ser acompañado en los casos difíciles o dudosos: «Pero si el caso no fuese arduo, ni de riesgo, no puede pedirlo, porque expone al enfermo a mayores gastos». Su recomendación va más allá: debe informar a los interesados de si le parece inútil la celebración de una consulta, aunque acepte la decisión que en este sentido adopte el paciente o la familia ${ }^{98}$.

Otra cuestión es la de los honorarios que percibían los consultores. No contamos con datos sobre la cuantía de las retribuciones devengadas por la realización de consultas $^{99}$. Lo que sí sabemos es que los honorarios estaban relacionados con el prestigio del consultor y que se solía retribuir de modo desigual a los médicos que participaban en la consulta. Fernando Oxea, por ejemplo, debió de percibir unos honorarios elevados porque en la polémica levantada a raíz de una consulta en la que participó, es éste uno de los argumentos a los que tiene que responder. Su oponente, para criticarle, afirma que el informe del médico mejor pagado no siempre es el más acertado, aunque sí al que más caso se hace. Y, en la defensa panfletaria que Marcos Seguín hace de Oxea contesta: «De aquí infiero que, si por una casualidad, Ortega tiene alguna consulta con los médicos de los barrios, o de los gremios de Madrid, como el de los zapateros, que también tiene su tal cual médico asalariado, le pagan menos, porque es mas corto de razones, por serlo de razón» ${ }^{100}$.

En esta misma línea está el acuerdo que, en 1793, adoptan los profesores de la Universidad de Salamanca cuando observaron que disminuía el número de pacientes y de la cuantía de los honorarios que percibían. El pacto consistió en tasar la consulta hecha por un catedrático entre veinte y cuarenta reales a los que se añadían las visitas extraordinarias y las certificaciones. Además, se comprometieron a no concurrir con los médicos de partido en consultas o juntas, y si llamaran a éstos, a retirarse con dignidad ${ }^{101}$.

\footnotetext{
97 LEÓN GÓMEZ (1744), pp. 18-19.

98 Ibidem, p. 18

99 Hemos encontrado el caso de un consultor que no recibió ninguna retribución por su informe. Se trata del Dr. Monravá quien por ser eclesiástico renuncia a la bonificación: «porque como soy eclesiástico, tengo orden del Santo Padre por breve expedito, para medicinar solamente de limosna a los pobres.» MONRAVA Y ROCA (1750), p. 249.

100 OXEA, F. (1788), Justa repulsa de una grosera, falsa calumnia, y descortés precipitado juicio, que hizo i manifestó D. José Ortega de Tamayo i Padilla, médico en la Corte, que lo fue de varios Partidos, en un Discurso Medico..., Santiago, p. 118.

101 PeSET, M.; PESET, J. L. (1974), La universidad española (siglos XVIII y XIX): despotismo ilustrado y revolución liberal, Madrid, p. 202.
} 


\section{LOS PERJUICIOS DE LAS CONSULTAS}

Son habituales las críticas que recibía en el siglo XVIII este modo de asistencia. Luque ya había recogido el eco: «Luego que ven muchos médicos juntos pronostican la fatalidad. De cierto enterrador he oído que, sólo porque vio en un zaguán muchas mulas de médicos, entró a pedir le socorrieran con dineros, por cuenta del entierro, que presto avia de hazer» ${ }^{102}$. Quizá el que se manifestó más crítico fue Gazola, para quien el colmo del embaucamiento que suponen las consultas es la confianza de las familias en el sistema. En efecto, era frecuente que la familia, cuando un enfermo no mejoraba tras el dictamen de una consulta, volviera a convocar otra, por lo que, a su parecer, se multiplicaban los errores ${ }^{103}$.

Gazola hizo una crítica global a los médicos, por lo que sus argumentos sirven sólo parcialmente; ya que, si bien es cierto que de la consulta practicada por malos médicos no se deriva éxito ninguno, lo mismo sucede con la asistencia practicada por cada uno por separado.

Ni detractores ni partidarios presentan como obstáculo el factor económico o la facilidad para disminuir la responsabilidad profesional de cada consultor. En cambio, destacan otras dos: la primera es que un dictamen aun siendo verdadero, puede ser rechazado por la mayoría de los consultores. Esta cuestión no es sólo teórica $-\mathrm{y}$ desde este punto de vista lo desarrolla Luque-, sino que tenemos un caso que le ocurrió a Mallén, cirujano rural, a quien el Dr. Aguilar no reconoce ${ }^{104}$; también Piquer se encuentra en la misma situación cuando acude a ver a Vicente Navarro Escrivano ${ }^{105}$; y Monravá achaca la muerte del conde de Luna a que no se siguiera su única opinión frente a los más de diez médicos convocados ${ }^{106}$.

Además, comentan los múltiples conflictos y polémicas que originan las consultas o juntas de médicos por la disparidad de los dictámenes o por la simple alteración de la prelación debida al médico consultor, todo lo cual iba en detrimento de la buena atención del enfermo ${ }^{107}$. Monravá, quizá como consecuencia de su mala experiencia,

102 LUQUe (1694), p. 9

103 «Pero no para aquí el engaño; pues si empeora el enfermo, tan lejos están sus familiares de conocer el yerro, que antes bien comenten otro mayor con llamar otros médicos de la misma clase, persuadiéndose que verán más muchos ojos que dos, sin advertir que, en las tinieblas, tanto no verá un ojo solo, como ciento». GAZOLA (1788), p. 40.

$104 C f r$. MALLEN Y CUEVAS (1715), p. 3.

105 Cfr. MAYÁns y Siscar, G. (1972), Epistolario I: Mayáns y los médicos. Transcripción y estudio V. PESET. Valencia, pp. 70, 76, 366, 472.

106 MONRAVA Y ROCA (1750), pp. 297-8.

107 Donde es de advertir, que de estas altercaciones se suelen seguir muy malas consequencias, como son, que en las consultas acaben en discordias, concluyan en disensiones, y riñas, y que en tan necias porfías, o llega tarde el remedio, o tal vez no llega; y que asimismo no permitiendo lo preciso, y momen- 
advertía que cuando dos dictámenes son muy contrarios es muy difícil llegar a un acuerdo: «son dos consultas ex diámetro opuestas. Ve aquí el enfermo puesto en balanza: equilibrialmente, sin que la voluntad determine, que la balanza cayga a una parte, ni a otra parte» ${ }^{108}$. Y la amarga opinión del Administrador del Hospital Real de Santiago acerca de las Juntas de los médicos era que las frecuentes disputas que suscitaba perjudicaba, y mucho, a los enfermos: «Siempre he observado que en las Juntas de los médicos, rara vez dejan de discrepar en los pareceres, y sin que jamás puedan ajustarse todos hallan razones en apoyo de la idea que concibieron; pues si ellos mismos entre sí no se convienen, caminando a un mismo fin, ¿cómo quiere V.S. que nos pongamos en argumentos con ellos pretendiendo que no sangren ni pongan cáusticos, cuando nos persuadirán de lo contrario con razones de su algarabía médica y no sacaríamos más fruto que haber perdido el tiempo inútilmente. Y aun cuando los juntáramos para decidir en este punto, quedaría de peor calidad; pues queriendo defender cada uno su partido, saldrían más enconados; y la ganancia sería recaer todos sistemas sobre los tristes pacientes» ${ }^{109}$.

Como hemos observado, un factor importante que influye en la disparidad de criterios en la resolución de las consultas son las diversas doctrinas médicas que se desarrollan en el XVIII, hasta el punto que hay quienes consideran que no es posible que puedan hacerse consultas entre médicos de movimientos diferentes porque necesariamente terminan en debates que no benefician precisamente al enfermo ${ }^{110}$. Además, las consultas - señalan - contribuían a separar más las posturas ya contrapuestas y dificultaban la permeabilidad de las ideas. También explican que la desconfianza ante la consulta médica, como en el caso de Gazola, en realidad no sea más que escepticismo hacia la medicina y los médicos en general.

Por otra parte, como también hemos advertido, los consultores aprovechan la publicación de las consultas para criticar a otros facultativos y lidiar las rencillas surgidas en el trato mutuo. Ya han ido saliendo algunos casos, entre los que sorprende el de Adeva por tratarse de un médico rural: en todas las Historias que él describe, los enfermos curan gracias a su sola intervención; y desprestigia a los otros médicos que trataron a los mismos enfermos llamándoles «médicos de segunda» ${ }^{111}$. Los enfrentamientos y pleitos surgidos a raíz de las consultas llevaron a intervenir a la autoridad

táneo de la ocasión estas dilaciones, lastimosamente se frustra el único fin a que tales médicos fueron convocados»), PELLAZ Y ESPINOSA (1708), p. 301.

108 MONRAVA Y ROCA (1750), p. 279.

109 Cfr. GARCÍA GUERRA, D. (1983), El Hospital Real de Santiago (1499-1804), Santiago, p. 93.

110 «Muchos siguen a Cartesio, otros a Willis; quien a Silvio de Boe, quien a Paracelso, quien a Elmoncio y quien todavía a Hipócrates y a Galeno. Pues si tal vez se juntan para la cura, o para la consulta de algún enfermo puede rogar a Dios de todo corazón, que le dé fortuna de que acierten con el remedio que ha de hacer bien, porque no haciéndose en semejantes casos cosa a derechas, viene a parar toda la consulta en debates». GAZOLA (1788), p. 109.

111 AdEVA Y PACHECO (1754), p. 26. 
constituida. Así lo relata Acuña: «Las discordias y pleytos que en puntos de presidencia ha habido, siempre ha procurado sossegarlos el Real Protomedicato y concordarlos, para que las Juntas se hagan con toda quietud, expidiendo para ello los Despachos necesarios, auxiliados del Real Consejo de Castilla» ${ }^{112}$.

Sin embargo, como hemos descrito en otro momento ${ }^{113}$, los partidarios de las consultas médicas no consideran que estos argumentos y los perjuicios derivados del modo de asistencia, sean de suficiente entidad como para no seguir recomendando la celebración de Juntas médicas, puesto que «los vulgares seguidores desta opinión más se oyen dicterios contra las consultas, que impugnaciones» ${ }^{114}$; lo que hay que hacer es aprender a practicarlas para que se desarrollen de modo adecuado. A esta opinión de Luque añade Pellaz su experiencia: «Pues considerando que el día de oy ay mucha falta en las consultas, tanto, que puedo asegurar, que en la cortedad de mis años lo tengo muy experimentado» ${ }^{115}$.

\section{CONCLUSIONES}

En los escritos sobre las consultas de los médicos españoles del siglo XVIII sobre las consultas existen referencias constantes a autores del pasado que son justificadas, puesto que tratan del médico y del modo de ejercer la medicina, cuestión que no habría cambiado, aunque sí lo hiciera el marco científico o técnico.

Estos autores fundamentan la realización de las consultas en el beneficio que proporciona a la asistencia de los enfermos, aunque, al mismo tiempo, coinciden en recomendar esta práctica por el provecho que supone para los facultativos: favorece la buena relación, evita malentendidos y es una manera de resolver los conflictos generados; aunque también se observa que de las consultas se derivaban, a veces, disputas y rivalidades entre los consultores.

Son abundantes las referencias a las cualidades del médico, ya que las condiciones ético-morales del consultor condicionaban el éxito de la práctica. Existía conciencia de la responsabilidad individual del médico consultor y encontramos referencias explícitas a la posibilidad de que se acogiera a la objeción de conciencia.

También era necesario poseer hábitos intelectuales. Estos autores introducen en su discurso la repercusión que tienen en la práctica cuestiones debatidas en ese momento y que guardan relación con la epistemología médica: el valor de la lógica, la posibilidad de la certeza en el conocimiento clínico o el escepticismo radical ante un juicio médico.

\footnotetext{
112 ACUÑA (1744), p. 144.

113 LEÓN SANZ (2002), p. 301.

114 LUQUE (1694), p. 9.

115 PeLlaZ Y ESPINOSA (1708), p. 2.
} 
Esta perspectiva se corresponde también con una mentalidad empírica, en la que la experiencia de casos anteriores es guía para actuar de una manera determinada.

Las dificultades que entrañaba esta práctica se refieren tanto a aspectos formales como es la prelación debida al médico consultor, cuanto a las consecuencias provenientes de la disparidad de criterios en la resolución de las consultas. Los enfrentamientos y pleitos surgidos a raíz de las consultas llevaron, en ocasiones, a la intervención de la autoridad. 